University of Nebraska - Lincoln

DigitalCommons@University of Nebraska - Lincoln

Faculty Publications from the Department of Electrical \& Computer Engineering, Department Electrical and Computer Engineering

2009

\title{
Coordinated Reactive Power Control of a Large Wind Farm and a STATCOM Using Heuristic Dynamic Programming
}

\author{
Wei Qiao \\ University of Nebraska-Lincoln, wqiao@engr.unl.edu \\ Ronald D. Harley \\ Georgia Institute of Technology \\ Ganesh Kumar Venayagamoorthy \\ Missouri University of Science and Technology
}

Follow this and additional works at: https://digitalcommons.unl.edu/electricalengineeringfacpub

Part of the Electrical and Computer Engineering Commons

Qiao, Wei; Harley, Ronald D.; and Venayagamoorthy, Ganesh Kumar, "Coordinated Reactive Power Control of a Large Wind Farm and a STATCOM Using Heuristic Dynamic Programming" (2009). Faculty Publications from the Department of Electrical and Computer Engineering. 132.

https://digitalcommons.unl.edu/electricalengineeringfacpub/132

This Article is brought to you for free and open access by the Electrical \& Computer Engineering, Department of at DigitalCommons@University of Nebraska - Lincoln. It has been accepted for inclusion in Faculty Publications from the Department of Electrical and Computer Engineering by an authorized administrator of DigitalCommons@University of Nebraska - Lincoln. 


\title{
Coordinated Reactive Power Control of a Large Wind Farm and a STATCOM Using Heuristic Dynamic Programming
}

\author{
Wei Qiao, Member, IEEE, Ronald G. Harley, Fellow, IEEE, \\ and Ganesh Kumar Venayagamoorthy, Senior Member, IEEE
}

\begin{abstract}
A novel interface neurocontroller (INC) is proposed for the coordinated reactive power control between a large wind farm equipped with doubly fed induction generators (DFIGs) and a static synchronous compensator (STATCOM). The heuristic dynamic programming (HDP) technique and radial basis function neural networks (RBFNNs) are used to design this INC. It effectively reduces the level of voltage sags as well as the over-currents in the DFIG rotor circuit during grid faults, and therefore, significantly enhances the fault ride-through capability of the wind farm. The INC also acts as a coordinated external damping controller for the wind farm and the STATCOM, and therefore, improves power oscillation damping of the system after grid faults. Simulation studies are carried out in PSCAD/EMTDC and the results are presented to verify the proposed INC.
\end{abstract}

Index Terms-Heuristic dynamic programming (HDP), interface neurocontroller (INC), power oscillation damping, reactive power control, static synchronous compensator (STATCOM), wind farm.

\section{INTRODUCTION}

B ECAUSE of the concern about the environmental pollution and a possible energy crisis, there has been a rapid increase in renewable energy sources worldwide in the past decade. Among various renewable energy sources, wind power is the most rapidly growing one.

Nowadays, the majority of wind turbines are equipped with doubly fed induction generators (DFIGs). In the DFIG concept, the wound-rotor induction generator is grid-connected at the stator terminals, as well as at the rotor mains via a partially rated variable frequency ac/dc/ac converter (VFC), which only needs to handle a fraction $(25 \%-30 \%)$ of the total power to achieve full control of the generator. The VFC consists of a rotor-side converter (RSC) and a grid-side converter (GSC) connected back-to-back by a dc-link capacitor.

Manuscript received July 12, 2006; revised February 5, 2008. First published January 13, 2009; current version published May 19, 2009. This work was supported in part by the National Science Foundation, USA, under Grant ECS 0524183. Paper no. TEC-00323-2006.

W. Qiao is with the Department of Electrical Engineering, University of Nebraska-Lincoln, Lincoln, NE 68588-0511 USA (e-mail: wqiao@ engr.unl.edu)

R. G. Harley is with the Intelligent Power Infrastructure Consortium (IPIC), School of Electrical and Computer Engineering, Georgia Institute of Technology, Atlanta, GA 30332-0250 USA (e-mail: rharley@ece.gatech.edu).

G. K. Venayagamoorthy is with the Real-Time Power and Intelligent Systems Laboratory, Department of Electrical and Computer Engineering, Missouri University of Science and Technology, Rolla, MO 65409-0249 USA (e-mail: gkumar@ieee.org).

Color versions of one or more of the figures in this paper are available online at http://ieeexplore.ieee.org.

Digital Object Identifier 10.1109/TEC.2008.2001456
In order to meet power factor requirement (e.g., -0.95 to $0.95)$ at the connection point, most wind farms are equipped with switched shunt capacitors for static reactive compensation [1], [2]. Moreover, because many wind farms are connected to electrically weak power networks, characterized by low short circuit ratios and under-voltage conditions, dynamic power electronic devices such as a static var compensator (SVC) and a static synchronous compensator (STATCOM) [3] have been increasingly used in wind farms to provide rapid and smooth reactive compensation and voltage control [4].

When connected to the grid and during a grid fault, the voltage sags at the connection point of the wind farm can cause a high current in the rotor circuit and the converter. Since the power rating of the VFC converter is only $25 \%-30 \%$ of the induction generator power rating, this over-current can lead to the destruction of the converter. Therefore, one of the key issues related to the wind farms equipped with DFIGs is the grid fault or low voltage ride-through capability. Much research effort has gone into this issue and several techniques have been proposed.

One technique is blocking the RSC and short circuiting the rotor circuit by a crow-bar circuit to protect the converter from over current in the rotor circuit [1], [5], [6]. The wind turbine generators (WTGs) continue their operation to produce some active power, and the GSCs can be set to control the reactive power and voltage. When the fault has been cleared and when the voltage and the frequency in the power network have been reestablished, the RSC restarts and the WTG returns to normal operation. In this uninterrupted operation feature, voltage stability is a crucial issue. In the case of a weak power network and during a grid fault, the GSC cannot provide sufficient reactive power and voltage support due to its small power capacity, and there can be a risk of voltage collapse. As a result, the RSC will not restart and the WTG will be disconnected from the network. This problem can be solved by using dynamic reactive compensation. In [6], the authors investigated the application of a STATCOM to help with the uninterrupted operation of a wind farm equipped with DFIGs during grid faults. However, the focus of [6] was to investigate the DFIG behavior with the STATCOM for voltage support during grid faults. In addition, the power network used in [6] is a simple single machine infinite bus system, and there is no coordination between the wind farm and the STATCOM for reactive power control.

The second solution to enhance the grid-fault ride-through capability of the DFIG wind turbines is to improve the control scheme of the RSC. A nonlinear controller and a fuzzy 


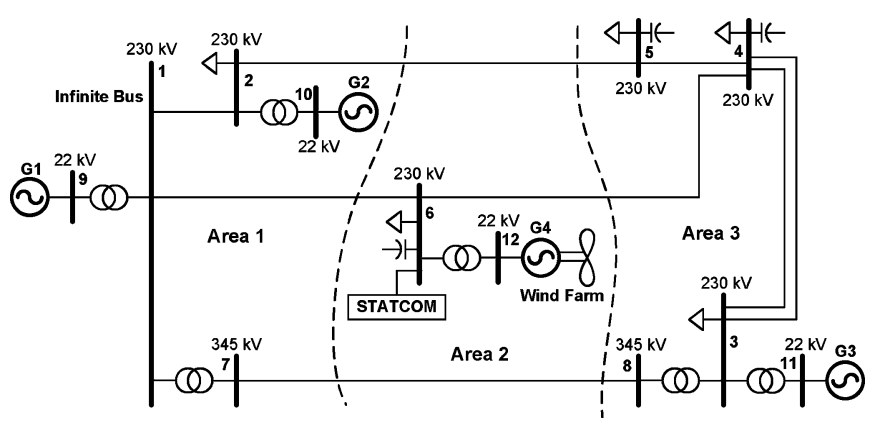

Fig. 1. Single-line diagram of the multimachine benchmark power system that includes a large wind farm and a STATCOM.

controller have been proposed in [7] and [8], respectively, for controlling the RSC. Compared with the conventional linear control schemes, these control schemes reduce the over current in the rotor circuit during grid faults.

Shunt flexible alternating current transmission system (FACTS) devices such as the SVC and the STATCOM provide rapid and smooth reactive compensation, and therefore, can reduce the level of voltage sags during grid faults. The application of a STATCOM to enhance the capability of a wind farm (equipped with DFIGs) to ride through grid faults in a multimachine power system has been reported in [9]. However, the reactive power control of the wind farm and the STATCOM in [9] are independent without coordination; during grid faults, the voltage control is only achieved by the STATCOM.

This paper extends the work of [9] by proposing a novel coordinated reactive power control scheme. It acts as an interface controller between a wind farm and a STATCOM. The heuristic dynamic programming (HDP) [10], [11] method and radial basis function neural networks (RBFNNs) [12] are employed to design this nonlinear optimal adaptive interface neurocontroller (INC). Simulation studies are carried out in PSCAD/EMTDC to verify the proposed INC.

\section{POWER SYSTEM MOdeL}

The original four-machine 12-bus benchmark power system in [13] is used as a platform system for studying FACTS device applications and integration of wind generation. Fig. 1 shows the single-line diagram of the extended four-machine 12-bus power system that now includes a large wind farm and a STATCOM. The system consists of six $230-\mathrm{kV}$ busses, two $345-\mathrm{kV}$ busses, and four $22-\mathrm{kV}$ busses. It covers three geographical areas. Area 1 is predominantly a generation area with most of its generation coming from hydro power (represented by G1 and G2). Area 2, located between the main generation area (area 1) and the main load center (area 3), has a large $400 \mathrm{MW}$ wind farm (represented by G4), but this is insufficient to meet local demand. Area 3, situated about $500 \mathrm{~km}$ from area 1, is a load center with some thermal generation (represented by G3). Furthermore, since the generation unit in area 2 has limited energy available, the system demand must often be satisfied through transmission. The transmission system consists of $230-\mathrm{kV}$ transmission lines except for one $345-\mathrm{kV}$ link between areas 1 and 3 (between busses 7 and 8).

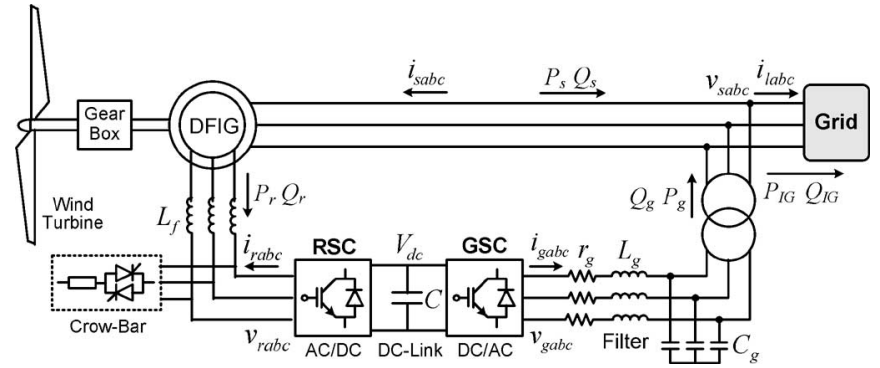

Fig. 2. Configuration of a DFIG wind turbine connected to a power grid.

Areas 2 and 3 have switched shunt capacitors to support the voltage. The detailed description of the system is given in [13].

A STATCOM is placed at bus 6 to provide steady state as well as transient voltage support for the wind farm. This dynamic reactive compensator provides fast and smooth voltage control for the wind farm and enhances the capability of the wind farm to ride through grid disturbances.

G1 is modeled as a three-phase infinite source, while the other two conventional generators (G2 and G3) are modeled in detail, with the exciter and turbine governor dynamics taken into account.

\section{WIND FARM MODEL}

The wind farm is represented by an aggregated model in which over 100 individual wind turbines and DFIGs are modeled as one equivalent DFIG driven by a single equivalent wind turbine [1], [9]. Each individual DFIG wind turbine represents a 3.6-MW WTG system [6], [14]. The parameters of the equivalent wind turbine and DFIG are given in the Appendix.

The basic configuration of a DFIG wind turbine connected to a power grid is shown in Fig. 2 [6], [9]. The wind turbine is connected to the induction generator through a mechanical shaft system, which consists of a low-speed shaft and a high-speed shaft and a gearbox in between. The wound-rotor induction machine in this configuration is fed from both stator and rotor sides. The stator is directly connected to the grid while the rotor is fed through a VFC. In order to produce electrical power at constant voltage and frequency to the utility grid over a wide operating range from subsynchronous to supersynchronous speed, the power flow between the rotor circuit and the grid must be controlled both in magnitude and in direction. Therefore, the VFC consists of two four-quadrant insulated-gate bipolar transistor (IGBT) pulse-width modulation (PWM) converters connected back-to-back by a dc-link capacitor. A crow-bar circuit is used to short circuit the RSC in order to protect the RSC from over current in the rotor circuit during transient disturbances.

\section{A. Wind Power Model}

The mechanical power of the turbine extracting from the wind is calculated by [1]:

$$
P_{m}=\frac{1}{2} \rho A_{r} v_{w}^{3} C_{P}(\lambda, \beta)
$$

where $\rho$ is the air density in $\mathrm{kg} / \mathrm{m}^{3}, A_{r}=\pi R^{2}$ is the area swept by the rotor blades in $\mathrm{m}^{2}, v_{w}$ is the wind speed in $\mathrm{m} / \mathrm{s}, C_{P}$ is the 


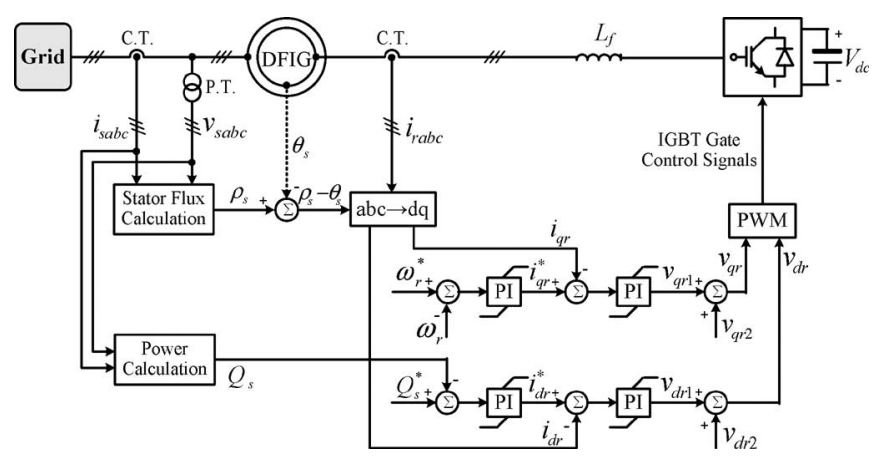

Fig. 3. Overall control scheme of the RSC: $v_{d r 2}=-s \omega_{s} \sigma L_{r} i_{q r}, v_{q r 2}=$ $s \omega_{s}\left(\sigma L_{r} i_{d r}+L_{m}^{2} i_{m s} / L_{s}\right), \sigma=1-L_{m}^{2} / L_{s} L_{r}$.

power coefficient, which is a function of both tip speed ratio $\lambda$ and the blade pitch angle $\beta$. The $C_{P}-\lambda-\beta$ curves depend on the blade design and are given by the wind turbine manufacturer.

\section{B. Modeling of the Shaft System}

In transient stability studies, the WTG shaft system should be represented by a two-mass model instead of a single lumpedmass model [1]. In the two-mass model, separate masses are used to represent the low-speed turbine and the high-speed generator, and the connecting resilient shaft is modeled as a spring and a damper. The motion equations are given by

$$
\begin{aligned}
& 2 H_{t} p \omega_{t}=T_{m}-D_{t} \omega_{t}-D_{t g}\left(\omega_{t}-\omega_{r}\right)-T_{t g} \\
& 2 H_{g} p \omega_{r}=T_{t g}+D_{t g}\left(\omega_{t}-\omega_{r}\right)-D_{g} \omega_{r}-T_{e} \\
& p T_{t g}=K_{t g}\left(\omega_{t}-\omega_{r}\right)
\end{aligned}
$$

where $p=d / d t ; \omega_{t}$ and $\omega_{r}$ are the turbine and generator rotor speed, respectively; $T_{m}$ and $T_{e}$ are the mechanical torque applied to the turbine and the electrical torque of the generator, respectively; $T_{t g}$ is an internal torque of the model; $H_{t}$ and $H_{g}$ are the inertia constants of the turbine and the generator, respectively; $D_{t}$ and $D_{g}$ are the damping coefficients of the turbine and the generator, respectively; $D_{t g}$ is the damping coefficient of the flexible coupling (shaft) between the two masses; and $K_{t g}$ is the shaft stiffness.

As discussed in [15], the WTG shaft system described by (2)-(4) has lightly damped low-frequency torsional oscillation modes. The natural frequencies of these modes depend on the mechanical parameters of the WTG systems, e.g., the inertia constants of the wind turbines and DFIGs, and are less than several hertz on most practical WTG systems.

\section{Control of the DFIG}

Control of the DFIG is achieved by control of the VFC, which includes control of the RSC and control of the GSC [1], [6], [15]. The objective of the RSC is to regulate both the stator active and reactive powers, $P_{s}$ and $Q_{s}$, independently. The reactive power control using the RSC can be applied to keep the stator voltage $V_{s}$ within the desired range, when the DFIG feeds into a weak power system with insufficient local reactive compensation. When the DFIG feeds into a strong power system, the command of $Q_{s}$ can be simply set to zero. Fig. 3 shows the

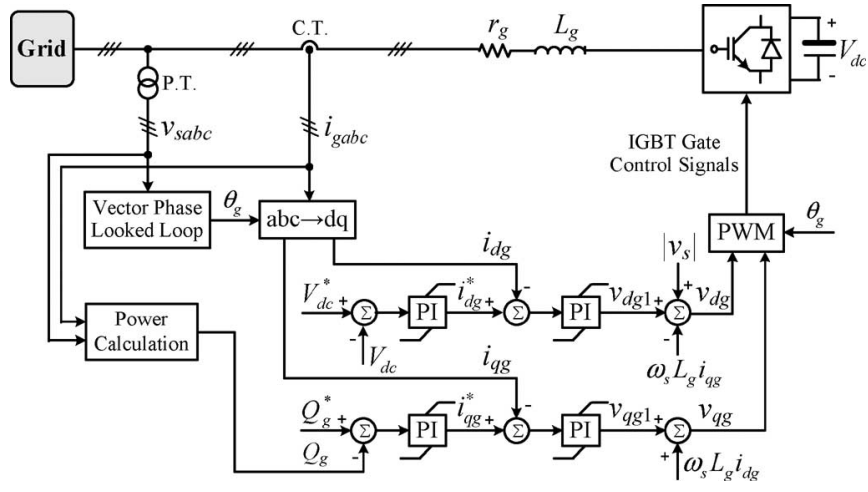

Fig. 4. Overall control scheme of the GSC.

overall vector control scheme of the RSC. In order to achieve independent control of the stator active power $P_{s}$ (by means of speed control) and reactive power $Q_{s}$ (see Fig. 2) by means of rotor current regulation, the instantaneous three-phase rotor currents $i_{r a b c}$ are sampled and transformed to $d q$ components $i_{d r}$ and $i_{q r}$ in the stator-flux oriented reference frame. The reference values for $i_{d r}$ and $i_{q r}$ can be determined directly from $Q_{s}$ and $\omega_{r}$ commands, respectively. The actual $d q$ current signals $\left(i_{d r}\right.$ and $\left.i_{q r}\right)$ are then compared with their reference signals $\left(i_{d r}^{*}\right.$ and $i_{q r}^{*}$ ) to generate the error signals, which are passed through two proportional-integral (PI) controllers to form the voltage signals $v_{d r 1}$ and $v_{q r 1}$. The two voltage signals $\left(v_{d r 1}\right.$ and $\left.v_{q r 1}\right)$ are compensated by the corresponding cross coupling terms $\left(v_{d r 2}\right.$ and $\left.v_{q r 2}\right)$ to form the $d q$ voltage signals $v_{d r}$ and $v_{q r}$. They are then used by the PWM module to generate the IGBT gate control signals to drive the rotor-side IGBT converter.

The objective of the GSC is to keep the dc-link voltage constant regardless of the magnitude and direction of the rotor power. In this paper, the GSC control scheme is also designed to regulate the reactive power, $Q_{g}$, exchanged between the GSC and the grid. During normal operation, the GSC is considered to be reactive neutral by setting $Q_{g}^{*}=0$. This consideration is reasonable because the VFC rating is only $25 \%-30 \%$ of the generator rating and the VFC is primarily used to supply the active power from the rotor to the power grid. However, the reactive power controllability of the GSC can be useful during the process of voltage reestablishment, after a grid fault has been cleared and the RSC has been blocked. Fig. 4 shows the overall control scheme of the GSC. The actual signals of the dc-link voltage and the reactive power $\left(V_{\mathrm{dc}}\right.$ and $\left.Q_{g}\right)$ are compared with their command values $\left(V_{\mathrm{dc}}^{*}\right.$ and $Q_{g}^{*}$ ) to form the error signals, which are passed through the PI controllers to generate the reference signals for the $d$-axis and $q$-axis current components $\left(i_{d g}^{*}\right.$ and $\left.i_{q g}^{*}\right)$, respectively. The instantaneous ac-side three-phase currents of the GSC are sampled and transformed into $d q$ current components $i_{d g}$ and $i_{q g}$ by applying the synchronously rotating reference frame transformation. The actual signals $\left(i_{d g}\right.$ and $\left.i_{q g}\right)$ are then compared with the corresponding reference signals to form the error signals, which are passed through two PI controllers. The voltage signals $\left(v_{d g 1}\right.$ and $\left.v_{q g 1}\right)$ are compensated by the corresponding cross coupling terms to form the $d q$ voltage signals $v_{d g}$ and $v_{q g}$. They are then used by 


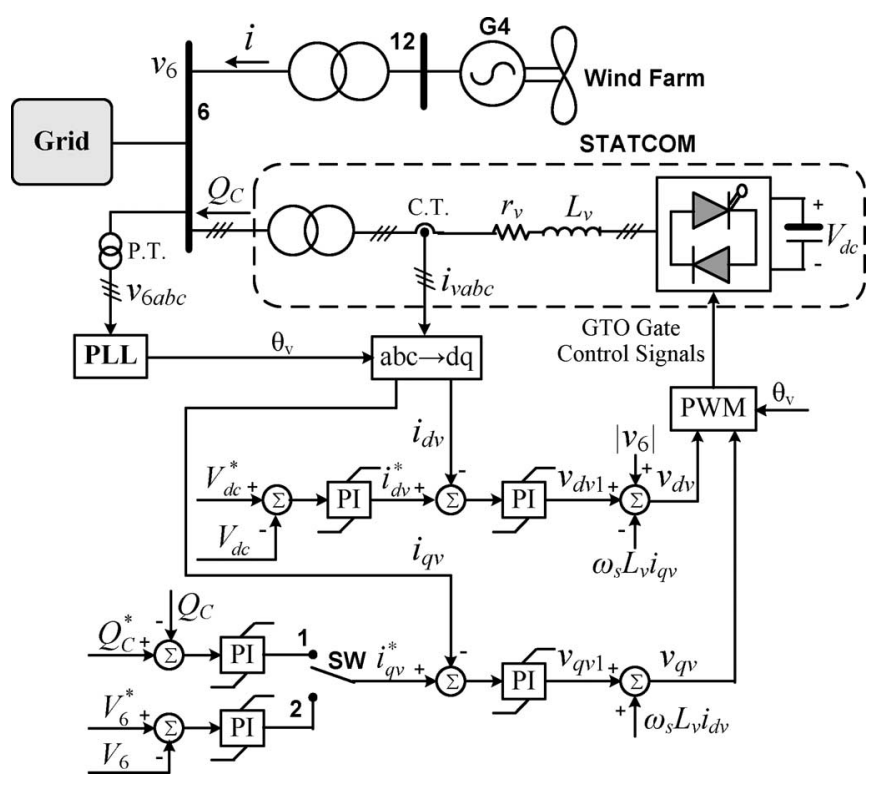

Fig. 5. Overall control scheme of the STATCOM.

the PWM module to generate the IGBT gate-control signals to drive the grid-side IGBT converter.

\section{STATCOM MODEL}

A STATCOM [3], [16], also known as an advanced SVC, is a shunt connected FACTS device. It generates a set of balanced three-phase sinusoidal voltages at the fundamental frequency, with rapidly controllable amplitude and phase angle. A typical application of a STATCOM is for voltage support. In this paper, the STATCOM is modeled as a gate-turn-off thyristor (GTO) PWM converter with a dc-link capacitor. The overall control scheme of the STATCOM is shown in Fig. 5. The objective of the STATCOM is to provide the desired amount of reactive compensation [with the switch (SW) in position 1 in Fig. 5] or to directly regulate the voltage at the point of common coupling (PCC) (bus 6) within the desired range (with SW in position 2 in Fig. 5). This can enhance the capability of the wind farm to ride through transient disturbances in the grid. The block "grid" in Fig. 5 denotes the power network (see Fig. 1) to which the wind farm and the STATCOM are connected.

\section{Design of THE INTERfACE NeUROCONTROLLER}

Grid faults, even far away from the location of the wind farm, can cause voltage sags at the connection point of the wind farm. This voltage sag will result in an imbalance between the turbine input power and the generator output power, and therefore, a high current in the stator windings of the DFIG. Because of the magnetic coupling between stator and rotor, this current will also flow in the rotor circuit and the converter. In addition, the power imbalance during the fault will excite low-frequency torsional oscillations on the WTG shaft system, which leads to oscillations of the shaft speed and the output active power. These oscillations are lightly damped if there is no specifically designed damping control for the WTG system.

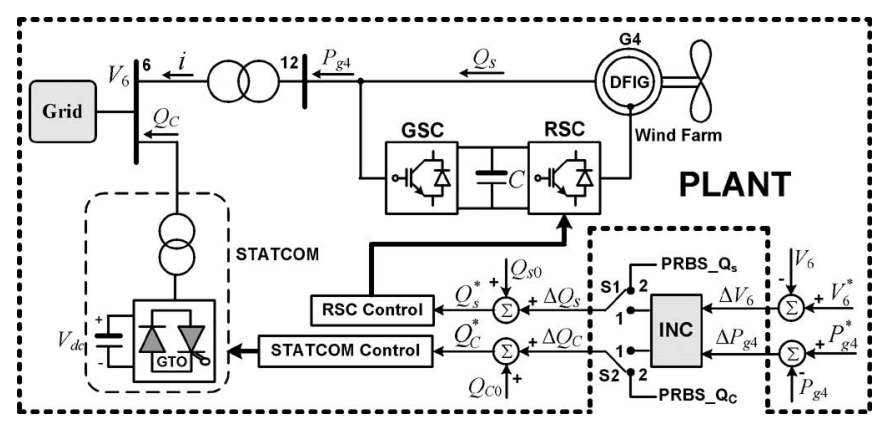

Fig. 6. Schematic diagram of the INC.

In this section, an adaptive critic design (ACD) approach, the HDP, and RBFNNs are used to design an external interface controller for the coordinated reactive power control between the wind farm and the STATCOM, as shown in Fig. 6. The dashed line block denotes the plant to be controlled by the INC. The voltage deviation, $\Delta V_{6}$, at bus 6 and the active power deviation, $\Delta P_{g 4}$, of the wind farm are fed into the INC to produce two supplementary control signals, $\Delta Q_{s}$ and $\Delta Q_{C}$. They are then added to the steady-state fixed set-point values, $Q_{s 0}$ and $Q_{C 0}$, respectively, to form the total commanded values of the compensating reactive power, $Q_{s}^{*}$ and $Q_{C}^{*}$, at the input of the RSC and the STATCOM controllers. A basic principle is that by rapidly varying the amount of reactive power provided by the DFIG and the STATCOM during grid faults, it is possible to reduce the level of voltage sags at the PCC, and therefore, control directly the transient imbalances between the electrical output power and the mechanical input power that are responsible for over current in the rotor circuit. Because of the direct coupling between voltage and reactive power, it is straightforward to use the voltage deviation, $\Delta V_{6}$, as an input signal of the INC. However, the active power deviation, $\Delta P_{g 4}$, of the wind farm is also used as an input of the INC because it provides the INC with additional information of the plant dynamics. In addition, $\Delta P_{g 4}$ contains the information of system oscillations and can therefore be used by the INC to damp postfault power oscillations of the system. The fixed set-point value $Q_{s 0}$ of the DFIG can be determined based on the desired stator side or the net power factor of the induction machine. The choice of $Q_{s 0}$ is also subject to the limit of the DFIG MVar rating. The value of $Q_{C 0}$ can be determined by the results of a power flow calculation at a specific operating point or to achieve some form of optimal power flow operation of the network.

The transfer functions from $\Delta V_{6}$ and $\Delta P_{g 4}$ to $\Delta Q_{s}$ and $\Delta Q_{C}$ are complex, nonlinear, and depend on the network topology. A neural network can solve this problem and avoids having to derive such analytical functions.

\section{A. Radial Basis Function Neural Network}

The neural networks used in this paper are three-layer RBFNNs with the Gaussian density function as the activation function in the hidden layer (see Fig. 7) [12]. The overall input-output mapping for the RBFNN, $\hat{f}: X \in R^{n} \rightarrow Y \in$ 


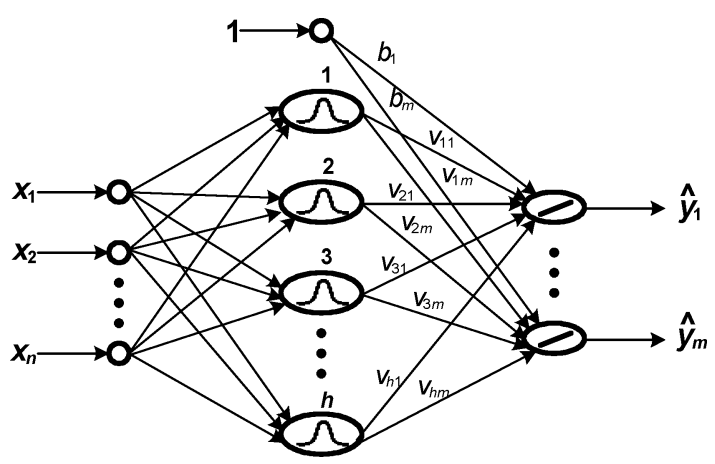

Fig. 7. Three-layer RBFNN.

$R^{m}$ is

$$
\hat{y}_{i}=b_{i}+\sum_{j=1}^{h} v_{j i} \exp \left(-\frac{\left\|x-C_{j}\right\|^{2}}{\beta_{j}^{2}}\right)
$$

where $x$ is the input vector, $C_{j} \in R^{n}$ is the center of the $j$ th radial basis function (RBF) units in the hidden layer, $h$ is the number of RBF units, $b_{i}$ and $v_{j i}$ are the bias term and the weight between hidden and output layers, respectively, and $\hat{y}_{i}$ is the $i$ th output.

The locations of RBF centers are determined offline using a $k$-means clustering algorithm [17]. Once the RBF centers are established, the width $\beta_{i}$ of the $i$ th RBF unit in the hidden layer is calculated as follows

$$
\beta_{i}=\left(\frac{1}{h} \sum_{j=1}^{h}\left\|C_{i}-C_{j}\right\|^{2}\right)^{1 / 2}
$$

where $C_{i}$ and $C_{j}$ are the center of the $i$ th and $j$ th RBF units, respectively. In (5) and (6), $\|\cdots\|$ represents the Euclidean norm.

\section{B. Adaptive Critic Designs and Heuristic Dynamic Programming}

ACDs, proposed by Werbos [10], is a neural-network-based optimization and control technique that solves the classical nonlinear optimal control problem by combining concepts of approximate dynamic programming and reinforcement learning.

Dynamic programming may provide the best approach to design the optimal control for highly constrained nonlinear systems [18]. In dynamic programming, such an optimal control is obtained by solving the Bellman equation that optimizes some cost-to-go function $J$ of the system, defined as

$$
J(k)=\sum_{q=0}^{\infty} \gamma^{q} U(k+q)=\gamma J(k+1)+U(k)
$$

where $U(\cdot)$ is the utility function (user-defined function) that represents the one-stage cost or performance measure function of the system at each time step, and $\gamma$ is a discount factor for finite horizon problems $(0<\gamma<1)$. Equation (7) describes the basic principle of dynamic programming: optimizing $J(\cdot)$ in the short term is equivalent to optimizing $U(\cdot)$ in the long term, and vice versa. This principle can be explained in more details as

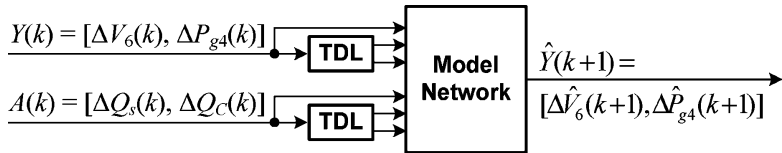

Fig. 8. Structure of the model network: TDL denotes time delay lock.

follows. If $J(k)$ is optimal, then $J(k+1)$ and $U(k)$ are both optimal; if $J(k+1)$ is optimal, then $J(k+2)$ and $U(k+1)$ are both optimal; and so on. In other words, if $J(k)$ is optimal, then $U(n)$, for $n=k, k+1, \ldots, \infty$, are all optimal, and vice versa. Therefore, if a control action optimizes the cost-to-go function $J(\cdot)$ at time step $k$, then it optimizes the utility function $U(\cdot)$ from time step $k$ and onward.

The conventional dynamic programming approaches require an accurate analytical model of the system dynamics, as well as knowledge of the system comprehensive dynamics known a priori to develop an appropriate cost function $J(\cdot)$. These however are normally unavailable for many complex nonlinear systems. Therefore, it is difficult to obtain an accurate solution (i.e., an optimal control) for such systems in dynamic programming. The ACD method offers an approach to find an approximate solution to dynamic programming.

The HDP, belonging to the family of ACDs, requires three neural networks, one for the model, one for the critic, and one for the action network for its implementation [10], [11]. The model network is used to provide a dynamical model of the plant for training the critic and action networks; the critic network estimates the cost function $J$ in (7); the action network provides the control action for the plant. Based on an accurate model network, the ACD method determines optimal control laws for a system by successively adapting the critic and action networks. The adaptation process starts with a nonoptimal control by the action network; the critic network then guides the action network toward the optimal solution at each successive adaptation. This adaptation process uses the concept of reinforcement learning. During the adaptations, neither of the networks needs any information of the desired control trajectory, only the desired cost needs to be known.

\section{Design of the Model Network}

The model network is a three-layer RBFNN with 25 hidden neurons. The plant inputs $A=\left[\Delta Q_{s}, \Delta Q_{C}\right]$ and outputs $Y=$ $\left[\Delta V_{6}, \Delta P_{g 4}\right]$ at time $k, k-1$, and $k-2$ are fed into the model network to estimate the plant outputs $\hat{Y}=\left[\Delta \hat{V}_{6}, \Delta \hat{P}_{g 4}\right]$ at time $k+1$, as shown in Fig. 8. The sampling period for the RBFNN implementation is $1 \mathrm{~ms}$.

The model network is pretrained offline using a suitably selected training data set collected from two sets of training. The first set is called forced training in which the plant is perturbed by injected small pseudorandom binary signals (PRBSs) (with $\mathrm{S} 1$ and $\mathrm{S} 2$ both in position 2 in Fig. 6), given by

$$
\begin{aligned}
\text { PRBS_Q } & (k)=\frac{0.1\left|Q_{s 0}\right|[r 0(k)+r 1(k)+r 2(k)]}{3} \\
\text { PRBS_Q } Q_{C}(k) & =\frac{0.1\left|Q_{C 0}\right|[r 0(k)+r 1(k)+r 2(k)]}{3}
\end{aligned}
$$


TABLE I

OPERATING CONDITIONS SELECTED FOR NATURAL TRAINING OF THE MODEL NETWORK

\begin{tabular}{c|c|c|c|c|c|c}
\hline $\begin{array}{c}\text { Operating } \\
\text { Conditions }\end{array}$ & $\boldsymbol{v}_{w}(\mathrm{~m} / \mathrm{s})$ & $\omega_{4}(\mathrm{pu})$ & $P_{g 4}(\mathrm{MW})$ & $\begin{array}{c}Q_{g} \\
(\mathrm{MVar})\end{array}$ & $\begin{array}{c}Q_{s} \\
(\mathrm{MVar})\end{array}$ & $\begin{array}{c}Q_{C} \\
(\mathrm{MVar})\end{array}$ \\
\hline OP-I & 11.6 & 1.2 & 350 & 0 & 0 & 150 \\
\hline OP-II & 11.0 & 1.2 & 300 & 0 & 0 & 165 \\
\hline OP-III & 11.4 & 1.15 & 250 & 0 & 38 & 150 \\
\hline OP-IV & 10.6 & 1.1 & 200 & 0 & 70 & 150 \\
\hline OP-V & 9.7 & 1.05 & 150 & 0 & 110 & 150 \\
\hline
\end{tabular}

where $r 0, r 1$, and $r 2$ are uniformly distributed random numbers in $[-1,1]$ with frequencies $0.5,1$, and $2 \mathrm{~Hz}$, respectively. The second set is called natural training in which the PRBS is removed (with S1 and S2 both in position 1 in Fig. 6), and the system is exposed to natural disturbances and faults in the power network. The forced training and natural training are carried out at several different operating points to form the training data set, given by

$$
\underline{\mathrm{A}}=\{\underline{\mathrm{X}}, \underline{\mathrm{Y}}\}=\left\{\bigcup_{i=1}^{m} \underline{\mathrm{A}}_{\mathrm{F} i}, \bigcup_{i=1}^{m} \bigcup_{j=1}^{n} \underline{\mathrm{A}}_{\mathrm{N} i j}\right\}
$$

where $\underline{\mathrm{A}}$ is the entire training data set selected from $m$ operating points; $\underline{X}$ and $\underline{Y}$ are the input and output data sets of the model network, respectively; $\underline{A}_{F i}$ is the subset collected from the forced training at the operating point $i$; $\underline{A}_{N i j}$ is the subset collected from the natural training caused by the $j$ th natural disturbance event at the operating point $i$. Table I shows the selected five operating points for the natural training of the model network in which $v_{w}, \omega_{4}, P_{g 4}, Q_{g}, Q_{s}$, and $Q_{C}$ are the wind speed, DFIG rotor speed, output active power of the wind farm, reactive power of the GSC, reactive power of the DFIG stator, and the compensated reactive power from the STATCOM, respectively. In this paper, three different natural disturbances are applied at each operating point in Table I: 1) a 150-ms temporary three-phase short circuit at the bus 1 end of line $1-6$;2) a 150 -ms temporary phase A to ground short circuit at the bus 4 end of one of the parallel lines 3-4; and 3) wind speed variations around the mean values in Table I using the wind model in [19], which causes the variations of $P_{g 4}$ in the range of $\pm 50 \mathrm{MW}$ at each operating point.

The selected training data set ensures that the model network can track the system dynamics over a wide operating range. After determining the training data set, the weights of the model network are then calculated by a least mean squares (LMS) method [20].

\section{Design of the Critic Network}

The critic network is a three-layer RBFNN with 15 hidden neurons. The inputs to the critic network are the estimated plant outputs, $\hat{Y}=\left[\Delta \hat{V}_{6}, \Delta \hat{P}_{g 4}\right]$, from the model network and its two time-delayed values. The output of the critic network is the estimate of the function $J$ in (7) with respect to the estimated plant output $\hat{Y}$, as shown in Fig. 9.

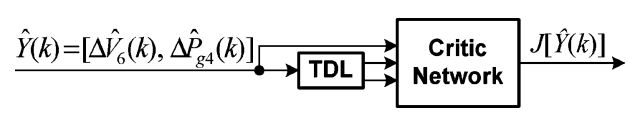

Fig. 9. Structure of the critic network.

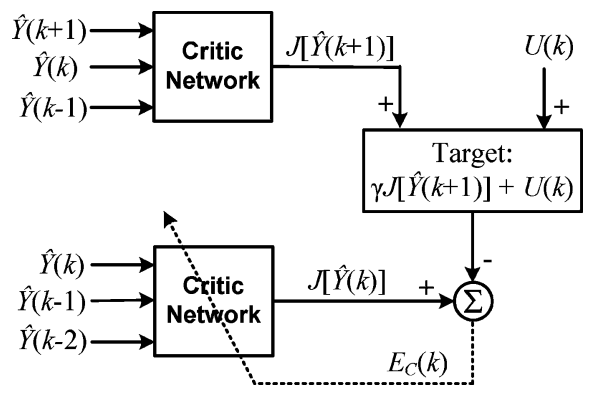

Fig. 10. Adaptation of the critic network in HDP.

The critic network learns to minimize the following error measure over time [11]:

$$
\left\|E_{C}\right\|=\frac{1}{2} \sum_{k} E_{C}^{T}(k) E_{C}(k)
$$

where

$$
E_{C}(k)=J[\hat{Y}(k)]-\gamma J[\hat{Y}(k+1)]-U(k) .
$$

The objective of the INC (see Fig. 6) is to provide an optimal coordinating control that minimizes the voltage deviations at bus $6, \Delta V_{6}$, as well as the active power oscillations, $\Delta P_{g 4}$, of the wind farm. Therefore, the utility function is defined as

$$
\begin{aligned}
U(k)= & \frac{1}{2}\left[\Delta V_{6}^{2}(k)+0.5 \Delta V_{6}^{2}(k-1)+0.1 \Delta V_{6}^{2}(k-2)\right] \\
& +\frac{1}{2}\left[\Delta P_{g 4}^{2}(k)+0.5 \Delta P_{g 4}^{2}(k-1)+0.1 \Delta P_{g 4}^{2}(k-2)\right] .
\end{aligned}
$$

In (13), it is natural to use time-delayed values of $\Delta V_{6}$ and $\Delta P_{g 4}$ because power systems are causal systems in which an output depends on the present as well as past input values.

Generally, two critic networks are required in HDP to estimate the cost-to-go function $J$ arising from the present state $\hat{Y}(k)$ and the future state $\hat{Y}(k+1)$, respectively. The critic's output $J(k+1)$ is necessary to generate the target signal $\gamma J(k+$ 1) $+U(t)$, for training the critic network. In the case of minimization in the LMS, the output weights of the critic network are updated by

$$
\Delta W_{C}(k)=-\eta_{C}\{J[\hat{Y}(k)]-\gamma J[\hat{Y}(k+1)]-U(k)\} \frac{\partial J[\hat{Y}(k)]}{\partial W_{C}}
$$

where $\eta_{C}$ is a positive learning gain. The adaptation of the critic network in HDP is shown in Fig. 10.

\section{E. Design of the Action Network}

The action network (see Fig. 11) is a three-layer RBFNN with 20 hidden neurons. The inputs to the action network are the plant outputs $Y=\left[\Delta V_{6}, \Delta P_{g 4}\right]$, at time $k-1, k-2$, and 


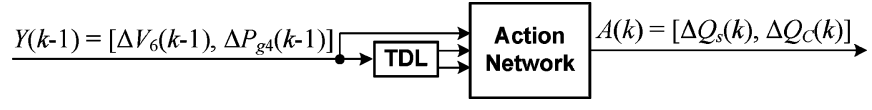

Fig. 11. Structure of the action network.

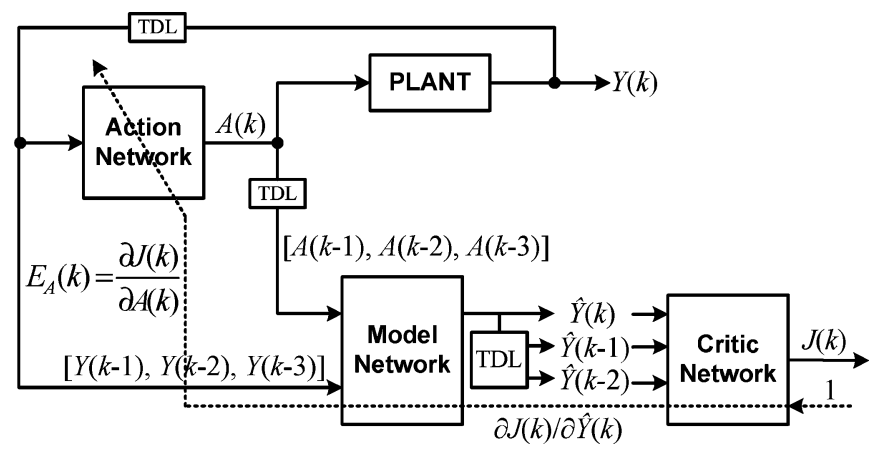

Fig. 12. Adaptation of the action network in HDP.

$k-3$. The outputs of the action network are the plant inputs, $A=\left[\Delta Q_{s}, \Delta Q_{C}\right]$, at time $k$.

The objective of the action network adaptation is to find out the optimal control trajectory, $A_{\mathrm{opt}}$, in order to minimize the cost-to-go function $J$ over time:

$$
A_{\mathrm{opt}}(k)=\arg \min _{A}[J(k)]=\arg \min _{A}[U(k)+\gamma J(k+1)] .
$$

Such adaptation, as shown in Fig. 12, is achieved by training the action network with the error signal, $E_{A}(k)=$ $\partial J(k) / \partial A(k)$, which is obtained by propagating the constant, $\partial J / \partial J=1$, back through the critic and model to the action network [11]. The output weights of the action network are then updated by

$$
\Delta W_{A}(k)=-\eta_{A} \frac{\partial J(k)}{\partial A(k)} \frac{\partial}{\partial W_{A}}\left[\frac{\partial J(k)}{\partial A(k)}\right] .
$$

\section{F. Overall Training Procedure}

The training procedure to implement the HDP algorithm consists of two training stages: one for the model network and the other for the critic/action networks. The model network is first pretrained offline to learn the plant dynamics before training the critic and action networks, as described in Section V-C. During the training of the critic and action networks, the wind speed is varied over a certain range (e.g., $\pm 2 \mathrm{~m} / \mathrm{s}$ around the mean wind speed) using the wind model in [19] to simulate the real operation of the wind farm. Consequently, the output active power of the wind farm varies significantly from time to time. During this time, the model network can be trained further to adapt to the operating conditions that are not covered by the pretraining.

The training stage of the critic/action networks contains two separate training cycles: one for the critic and the other for the action. The critic network is first pretrained by the procedure in Fig. 10 to approximate the cost-to-go function $J$. During

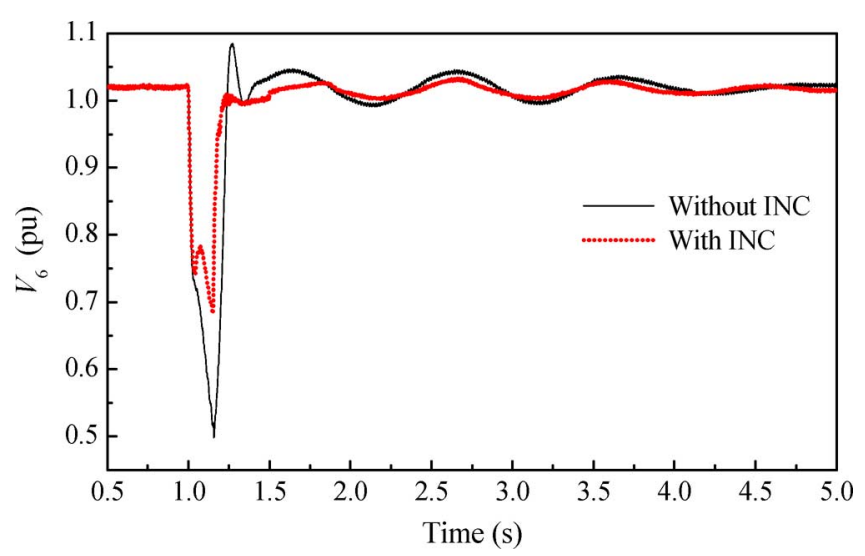

Fig. 13. Comparison of the voltage magnitude at bus 6 with and without the INC (STATCOM in reactive power control mode in the case of no INC).

the critic's pretraining, the plant is perturbed by injecting small PRBS given by (8) and (9) to $Q_{s 0}$ and $Q_{C 0}$, respectively (with $\mathrm{S} 1$ and $\mathrm{S} 2$ both in position 2 in Fig. 6).

Once the critic's pretraining is over, S1 and S2 switch to position 1 and the INC is used to provide an external control for the STATCOM and the RSC of the DFIG. Then, the critic's weights are fixed, the action network is trained by the procedure in Fig. 12 for $N_{A}$ cycles. Then, the action's weights are fixed, and the critic network is trained further for $N_{C}$ cycles. This process of training the critic/action networks is repeated one after the other until an accepted performance is achieved. Once the critic and action networks' weights have converged, the action network with the fixed weights is used to control the plant during the real-time operation.

\section{Simulation Results}

Simulation studies are carried out in this section to examine the proposed INC. The wind farm initially operates at an operating point with the wind speed $v_{w}=11.0 \mathrm{~m} / \mathrm{s}$, generator rotor speed $\omega_{4}=1.2 \mathrm{pu}$, output active power $P_{g 4}=300 \mathrm{MW}$, and output reactive power $Q_{g 4}=0$. The reactive power command of the GSC is set at $Q_{g}^{*}=0$. The steady-state fixed reactive power commands of the RSC and the STATCOM are set at $Q_{s 0}=0$ and $Q_{C 0}=165$ MVar, respectively. The voltage at bus 6 is regulated at $V_{6}=1.02 \mathrm{pu}$. A three-phase short circuit is applied to the bus 1 end of line 1-6 at $1 \mathrm{~s}$ and is cleared after $150 \mathrm{~ms}$. This scenario has been used in the pretraining of the model network, but has not been used for training the critic and action networks. The dynamic performance of the wind farm, reinforced with the INC, is compared with the cases without the INC.

\section{A. STATCOM in Reactive Power Control Mode in the Case of No INC}

Figs. 13-15 compare the system responses with and without the INC. In the case of no INC, the reactive power control is applied to the STATCOM (with SW in position 1 in Fig. 5). In this case, the reactive power commands of the RSC and the STATCOM are both constant. This control arrangement cannot 


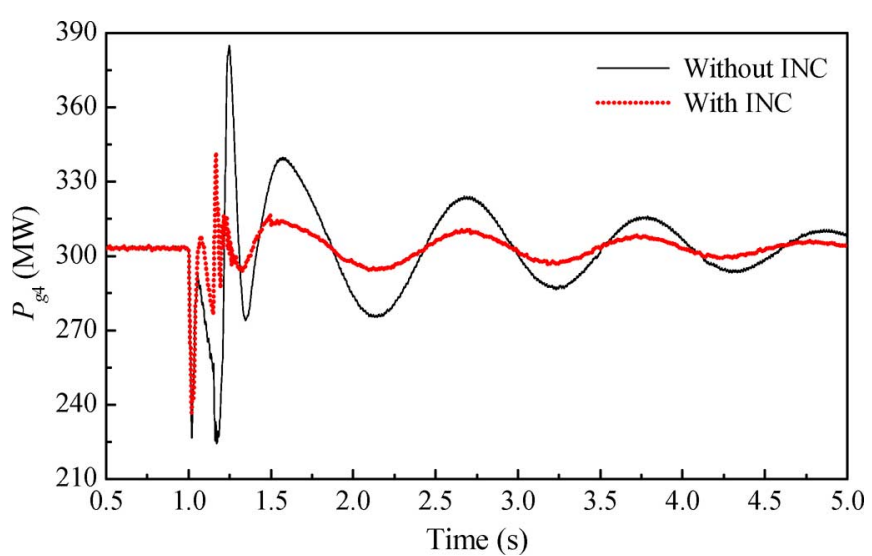

Fig. 14. Comparison of the output active power of the wind farm with and without the INC (STATCOM in reactive power control mode in the case of no INC).

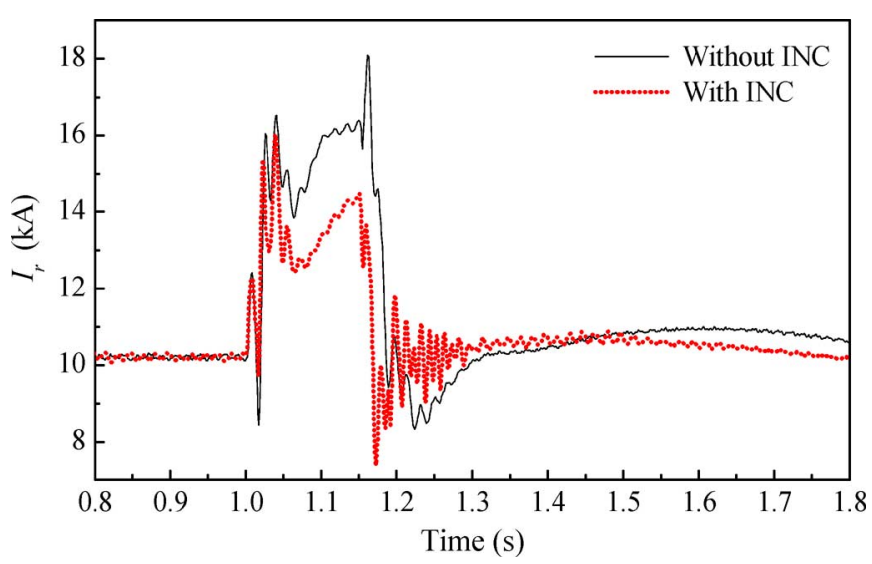

Fig. 15. Comparison of the DFIG rotor current magnitude with and without the INC (STATCOM in reactive power control mode in the case of no INC).

contribute to improving the transient behavior of the wind farm or the damping of power oscillations in the system. On the contrary, the INC provides the RSC and the STATCOM with supplementary control capability in response to voltage sags and power oscillations during a transient disturbance. As shown in Fig. 13, the INC significantly reduces the magnitudes of voltage sag and voltage overshot at bus 6 during the three-phase short circuit. Fig. 14 shows the output active power of the wind farm. By using the active power deviation signal, $\Delta P_{g 4}$, as an input to the INC, the power oscillation damping with the INC is much better than that without the INC. Finally, the magnitudes of the DFIG rotor current, $I_{r}$, are shown in Fig. 15. In this test, the reference values of the DFIG rotor currents, $i_{d r}^{*}$ and $i_{q r}^{*}$ in Fig. 3, are limited to 6.5 and $16 \mathrm{kA}$ for both cases with and without the INC. The peak value of the transient rotor current (from $1.05 \mathrm{~s}$ onward) without using the INC is about $18 \mathrm{kA}$, while this value reduces to $14 \mathrm{kA}$ when using the INC. The INC significantly reduces the magnitude of the DFIG rotor current transient during the $150 \mathrm{~ms}$ short circuit. Therefore, it enhances the fault ride-through capability of the wind farm.

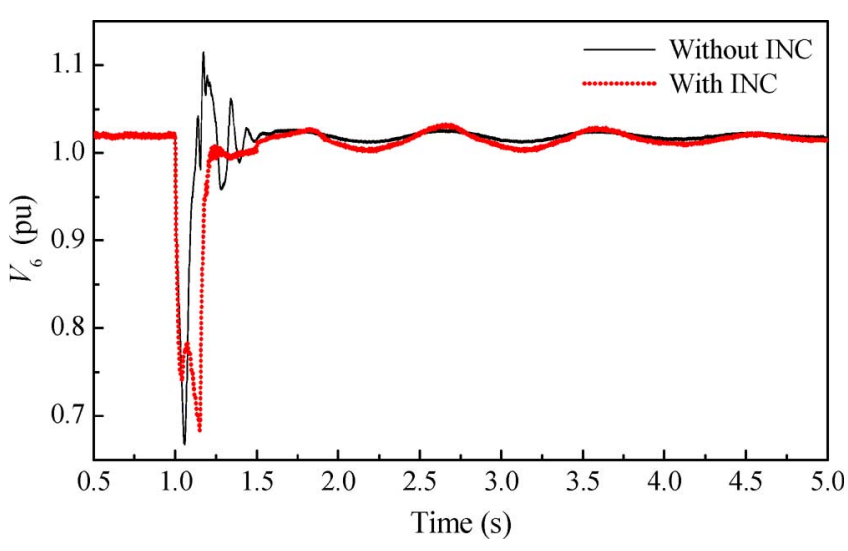

Fig. 16. Comparison of the voltage magnitude at bus 6 with and without the INC (STATCOM in voltage control mode in the case of no INC).

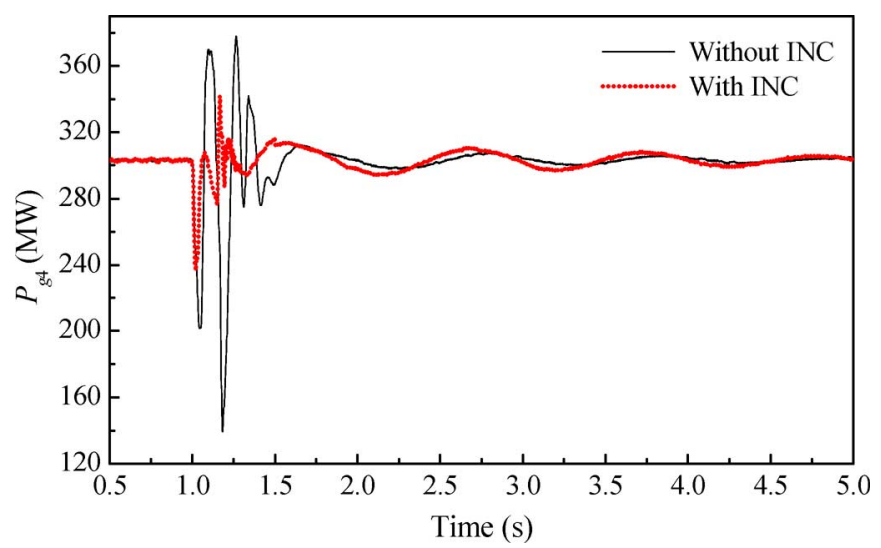

Fig. 17. Comparison of the output active power of the wind farm with and without the INC (STATCOM in voltage control mode in the case of no INC).

\section{B. STATCOM in Voltage Control Model in the Case of No INC}

Now the voltage control is applied to the STATCOM (with $\mathrm{SW}$ in position 2 in Fig. 5). In this case, the reactive power command of the RSC is still constant, but the STATCOM controller can contribute to improving the transient behavior of the wind farm during voltage sags. As shown in Figs. 16-18, the voltage sag at bus 6 (see Fig. 16) and the maximum rotor current (see Fig. 18) are almost the same for both cases with and without the INC; however, the voltage overshoot (see Fig. 16) and the magnitude of active power oscillations (see Fig. 17) in the case of the INC are much smaller than for no INC. These results are consistent with the design objectives, namely, the INC is optimally designed to minimize the voltage deviation at bus 6 as well as the magnitudes of active power oscillations in terms of the utility function $U$ in (13).

Another important result is shown in Fig. 19. It indicates that the amount of the compensated reactive power required by the STATCOM when using the INC is less than half of that without the INC. Therefore, the size of the STATCOM can be significantly reduced when using the INC to provide the coordinated reactive power control for the wind farm and the STATCOM. 


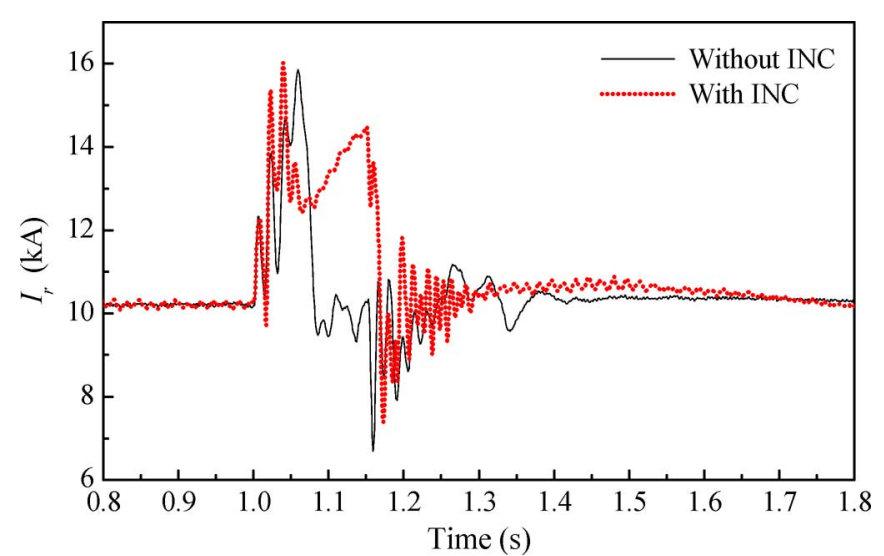

Fig. 18. Comparison of the DFIG rotor current magnitude with and without the INC (STATCOM in voltage control mode in the case of no INC).

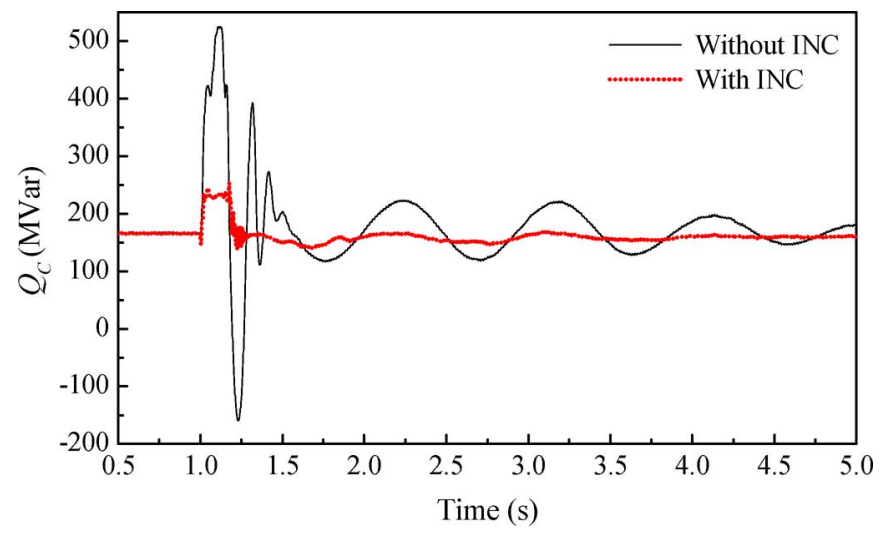

Fig. 19. Comparison of the compensated reactive power by the STATCOM with and without the INC (STATCOM in voltage control mode in the case of no INC).

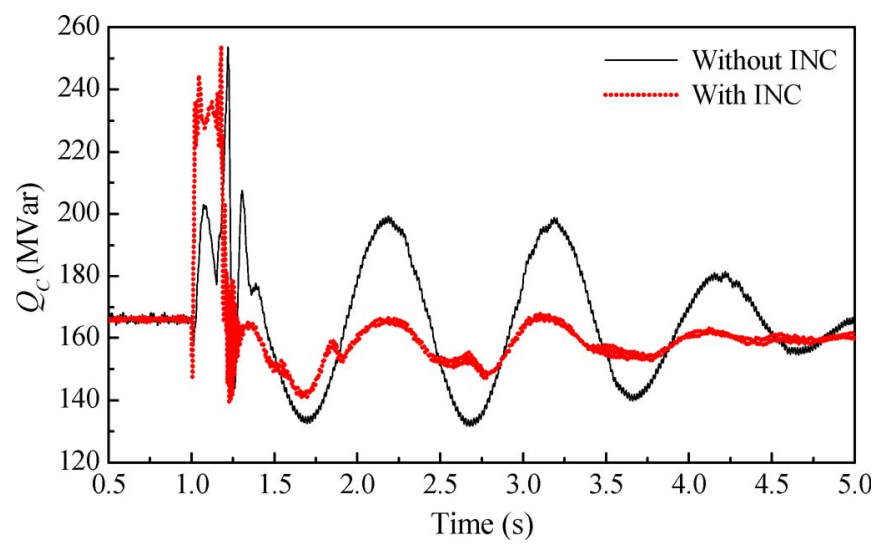

Fig. 20. Comparison of the compensated reactive power by the STATCOM with and without the INC (STATCOM in voltage control mode with reactive power limitation in the case of no INC).

More reactive compensation from the STATCOM in the case of no INC (see Fig. 19) contributes to the rapid decay of the rotor current transient (see Fig. 18). On the other hand, in terms of the utility function (13), the INC actually optimally controls the reactive compensation from the RSC and the STATCOM to decay (or damp) the voltage $\left(V_{6}\right)$ and active power $\left(P_{g 4}\right)$ transients as fast as possible. In this design, fast decay of the

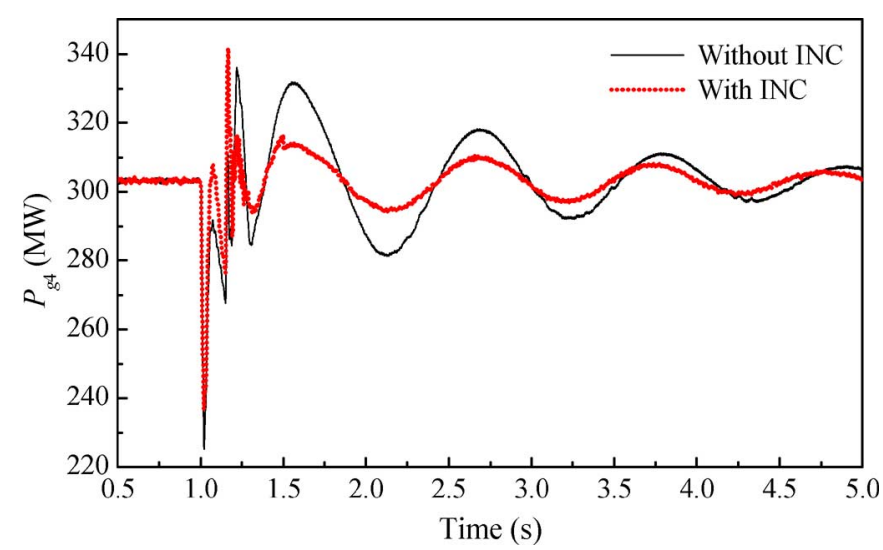

Fig. 21. Comparison of the output active power of the wind farm with and without the INC (STATCOM in voltage control mode with reactive power limitation in the case of no INC).

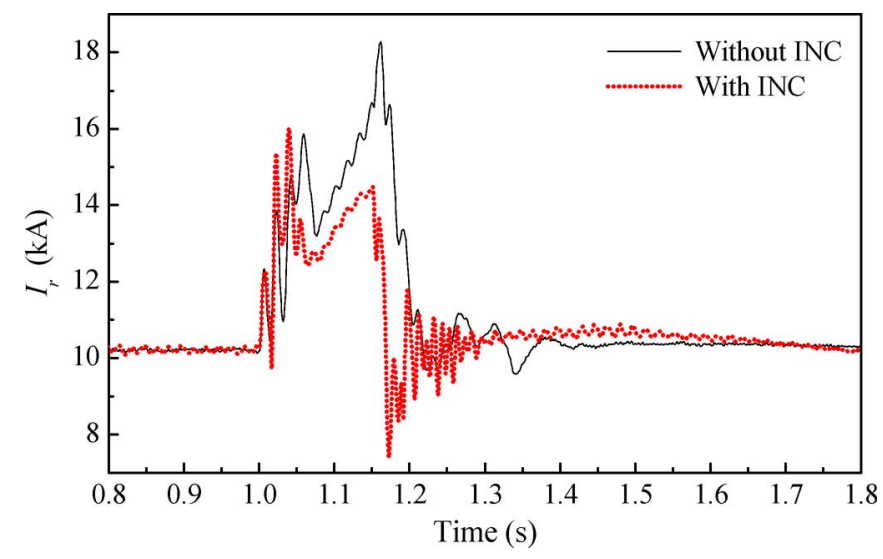

Fig. 22. Comparison of the DFIG rotor current magnitude with and without the INC (STATCOM in voltage control mode with reactive power limitation in the case of no INC).

rotor current $\left(I_{r}\right)$ transient is not a control objective of the INC, but the rotor current is always controlled within its limit (e.g., $16 \mathrm{kA}$ in this application) during the $150 \mathrm{~ms}$ grid fault, as shown in Fig. 18. Moreover, the postfault rotor currents (from $1.15 \mathrm{~s}$ ) decay rapidly for both cases with and without the INC.

\section{STATCOM in Voltage Control Mode With Reactive Power Limitation in the Case of No INC}

In this test, the STATCOM is still operated in the voltage control mode (with SW in position 2 in Fig. 5), but now the compensated reactive power $Q_{C}$ of the STATCOM is limited to 250 MVar (by putting suitable limits to the current references $i_{d v}^{*}$ and $i_{q v}^{*}$ in Fig. 5). Fig. 20 indicates that the maximum values of $Q_{C}$ are limited to 250 MVar for both cases with and without the INC. However, the postfault power oscillations of $Q_{C}$ (see Fig. 20) and $P_{g 4}$ (see Fig. 21) in the case of the INC are damped more rapidly than for no INC. In addition, the peak value of the rotor current transient is reduced when using the INC, as shown in Fig. 22. These results again confirm that the INC provides a smart coordinating control for the system. It improves the fault ride-through capability of the wind farm and power oscillation damping of the system during this transient disturbance. 


\section{CONCLUSION}

A large wind farm equipped with DFIGs connected to a multimachine benchmark power system has been modeled in the PSCAD/EMTDC environment. A STATCOM has been placed at the bus where the wind farm is connected to the power network for steady-state and transient reactive power compensation. The control schemes of the DFIG RSC, GSC, and the STATCOM have been suitably designed.

A novel INC, based on the HDP approach and RBFNNs, has been designed for the coordinated reactive power control between the wind farm and the STATCOM. Simulation studies have been carried out to examine the performance of the proposed INC during grid faults. Results have shown that the INC effectively reduced the level of voltage sags as well as the over currents in the DFIG rotor circuit during grid faults, and therefore, significantly enhanced the fault ride-through capability of the wind farm. Moreover, the INC acts as a coordinated external damping controller for the wind farm and the STATCOM, and therefore, improves the postfault power oscillation damping of system.

\section{APPENDIX}

Equivalent wind turbine: rated capacity $=400 \mathrm{MW}$, number of blades $=3$, rotor speed $($ variable $)=8.5-15.3 \mathrm{rpm}$.

Mechanical shaft system (on $400 \mathrm{MW}$ base): $H_{t}=4.29 \mathrm{~s}$, $H_{g}=0.9 \mathrm{~s}, D_{t}=D_{g}=0, D_{t g}=1.5 \mathrm{pu}, K_{t g}=296.7 \mathrm{pu}$.

Equivalent wound rotor induction generator: rated power $=400 \mathrm{MW}$, rated stator voltage $=22 \mathrm{kV}$, power factor $p f=-0.9$ to $+0.9, \quad r_{s}=0.0079 \mathrm{pu}, \quad r_{r}=0.025$ $\mathrm{pu}, L_{l s}=0.07937 \mathrm{pu}, L_{l r}=0.40 \mathrm{pu}, L_{m}=4.4 \mathrm{pu}$, base frequency $f=60 \mathrm{~Hz}$.

\section{REFERENCES}

[1] V. Akhmatov, "Analysis of dynamic behavior of electric power systems with large amount of wind power" Ph.D. dissertation, Tech. Univ. Denmark, Kgs. Lyngby, Denmark, Apr. 2003.

[2] J. Hochheimer, "Wind generation integration \& operation-Technical challenges/issues," in Proc. IEEE PES General Meet. 2006, Montreal, Canada.

[3] N. G. Hingorani and L. Gyugyi, Understanding FACTS: Concepts and Technology of Flexible AC Transmission Systems. New York: IEEE, 2000.

[4] S. W. Steven, "Wind parks as power plants," in Proc. IEEE PES General Meet. 2006, Montreal, Canada.

[5] J. Morren and S. W. H. de Haan, "Ridethrough of wind turbines with doubly-fed induction generator during voltage dip," IEEE Trans. Energy Convers., vol. 20, no. 2, pp. 435-441, Jun. 2005.

[6] W. Qiao, G. K. Venayagamoorthy, and R. G. Harley, "Real-time implementation of a STATCOM on a wind farm equipped with doubly fed induction generators," in Proc. IEEE IAS 41st Annu. Meet., Tampa, FL, Oct. 8-12, 2006, pp. 1073-1080.

[7] A. Mullane, G. Lightbody, and R. Yacamini, "Wind-turbine fault ridethrough enhancement," IEEE Trans. Power Syst., vol. 20, no. 4, pp. 19291937, Nov. 2005.

[8] R. G. de Almeida, J. A. P. Lopes, and J. A. L. Barreiros, "Improving power system dynamic behavior through doubly fed induction machines controlled by static converter using fuzzy control," IEEE Trans. Power Syst., vol. 19, no. 4, pp. 1942-1950, Nov. 2004.

[9] W. Qiao, R. G. Harley, and G. K. Venayagamoorthy, "Effects of FACTS devices on a power system which includes a large wind farm," in Proc. IEEE PES Power Syst. Conf. Expo. 2006, Atlanta, GA, pp. 2070-2076.

[10] P. J. Werbos, "Approximate dynamic programming for real-time control and neural modeling," in Handbook of Intelligent Control, D. White and D. Sofge, Eds. New York: Van Nostrand Reinhold, 1992, pp. 493-526.
[11] D. V. Prokhorov and D. C. Wunsch, "Adaptive critic designs," IEEE Trans. Neural Netw., vol. 8, no. 5, pp. 997-1007, Sep. 1997.

[12] W. Qiao and R. G. Harley, "Indirect adaptive external neuro-control for a series capacitive reactance compensator based on a voltage source PWM converter in damping power oscillations," IEEE Trans. Ind. Electron., vol. 54, no. 1, pp. 77-85, Feb. 2007.

[13] S. Jiang, U. D. Annakkage, and A. M. Gole, "A platform for validation of FACTS models," IEEE Trans. Power Del., vol. 21, no. 1, pp. 484-491, Jan. 2006.

[14] N. W. Miller, W. W. Price, and J. J. Sanchez-Gasca, "Dynamic modeling of GE 1.5 and 3.6 wind turbine-generators," in GE-Power Systems Energy Consulting. Schenectady, NY: General Electric International, Oct. 27, 2003.

[15] W. Qiao, W. Zhou, J. M. Aller, and R. G. Harley, "Wind speed estimation based sensorless output maximization control for a wind turbine driving a DFIG," IEEE Trans. Power Electron., vol. 23, no. 3, pp. 1156-1169, May 2008.

[16] C. Schauder and H. Mehta, "Vector analysis and control of advanced static VAR compensators," Inst. Elect. Eng. Proc.-Generation, Transmiss. Distrib., vol. 140, no. 4, pp. 299-306, Jul. 1993.

[17] K. Alsabti, S. Ranka, and V. Singh, "An efficient k-means clustering algorithm," presented at the First Workshop High Perform. Data Mining, Orlando, FL, Mar. 1998.

[18] D. A. White and M. I. Jordan, "Optimal control: A foundation for intelligent control," in Handbook of Intelligent Control, D. White and D. Sofge, Eds. New York: Van Nostrand Reinhold, 1992, pp. 185-214.

[19] W. Qiao, R. G. Harley, and G. K. Venayagamoorthy, "Dynamic modeling of wind farms with fixed-speed wind turbine generators," in Proc. IEEE PES 2007 General Meet., Tampa, FL.

[20] S. S. Haykin, Neural Networks: A Comprehensive Foundation, 2nd ed. Englewood Cliffs, NJ: Prentice-Hall, 1998.

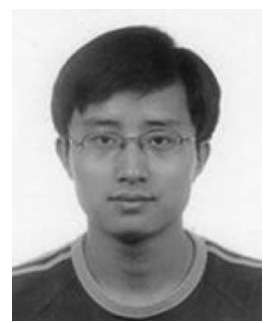

Wei Qiao (S'05-M'08) received the B.Eng. and M.Eng. degrees in electrical engineering from Zhejiang University, Hangzhou, China, in 1997 and 2002, respectively, the M.S. degree in high performance computation for engineered systems from SingaporeMIT Alliance (SMA), Singapore, in 2003, and the Ph.D. degree in electrical engineering from Georgia Institute of Technology, Atlanta, in 2008.

From 1997 to 1999, he was an Electrical Engineer in China Petroleum and Chemical Corporation (SINOPEC). Currently, he is an Assistant Professor of Electrical Engineering at the University of Nebraska-Lincoln. His research interests include renewable energy systems and distributed generation, microgrids, power system control, stability and performance optimization, power electronics, electric machines, flexible ac transmission systems (FACTS) devices, and the application of computation intelligence in electric energy systems. He is the author or coauthor of more than 30 papers published in refereed journals and international conferences and two book chapters.

Dr. Qiao is the Technical Program Co-Chair of the 2009 IEEE Symposium on Power Electronics and Machines in Wind Applications. He was the recipient of the first prize in the Student Paper and Poster Competition of the IEEE Power Engineering Society General Meeting 2006 in Montreal, Canada.

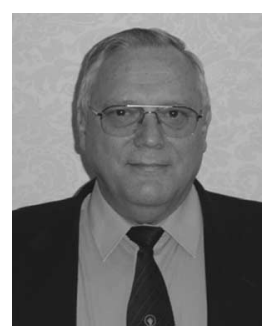

Ronald G. Harley (M'77-SM'86-F'92) received the M.Sc.Eng. degree (cum laude) in electrical engineering from the University of Pretoria, Pretoria, South Africa, in 1965, and the Ph.D. degree in electrical engineering from London University, London, U.K., in 1969.

During 1971, he was the Chair of Electrical Machines and Power Systems at the University of Natal, Durban, South Africa. He is currently the Duke Power Company Distinguished Professor at the Georgia Institute of Technology, Atlanta. His current research interests include the dynamic behavior and condition monitoring of electric machines, motor drives, power systems and their components, and controlling them by the use of power electronics and intelligent control algorithms. He is the author or coauthor of some 400 papers published in refereed journals and international conferences and three patents.

Prof. Harley was one of the IEEE Industry Applications Society's six Distinguished Lecturers during 2000 and 2001. He was the recipient of the Cyril Veinott Electromechanical Energy Conversion Award from the IEEE Power Engineering Society for "Outstanding contributions to the field of electromechanical energy conversion" in 2005. 


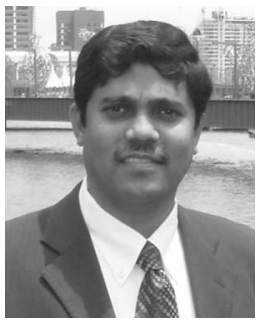

Ganesh Kumar Venayagamoorthy (S'91-M'97SM'02) received the Ph.D. degree in electrical engineering from the University of KwaZulu Natal, Durban, South Africa, in February 2002.

$\mathrm{He}$ is currently an Associate Professor of Electrical and Computer Engineering and the Director of the Real-Time Power and Intelligent Systems Laboratory, Missouri University of Science and Technology (Missouri S\&T), Rolla. During 2007, he was a Visiting Researcher at the ABB Corporate Research, Vasteras, Sweden. He has attracted in excess US $\$ 4$ Million in competitive research funding from external funding agencies. His current research interests include the development and applications of computational intelligence for power systems stability and control, alternative sources of energy, and flexible alternating current transmission systems (FACTS) devices. $\mathrm{He}$ is the author or coauthor of more than 57 refereed journals papers, 200 refereed international conference proceeding papers, two edited books, and five book chapters.
Dr. Venayagamoorthy is the Chair of the Working Group on Intelligent Control Systems and the Secretary of the Intelligent Systems subcommittee of the IEEE Power Engineering Society. He is the General Chair of 2008 IEEE Swarm Intelligence Symposium and the Program Chair of the 2009 IEEE-International Neural Network Society (INNS) International Joint Conference on Neural Networks. He was the recipient of the 2007 U.S. Office of Naval Research Young Investigator Program Award, the 2004 National Science Foundation CAREER Award, the 2006 IEEE Power Engineering Society Walter Fee Outstanding Young Engineer Award, the 2005 IEEE Industry Applications Society (IAS) Outstanding Young Member Award, the 2003 INNS Young Investigator Award, and the 2007/2005 Missouri S\&T Faculty Excellence Award. 